\title{
High expression of NR1D1 is associated with good prognosis in triple-negative breast cancer patients treated with chemotherapy
}

\author{
Hyelin $\mathrm{Na}^{1}$, Jinil Han², Na-Lee Ka ${ }^{1}$, Min-Ho Lee ${ }^{1}$, Yoon-La Choi ${ }^{3}$, Young Kee Shin ${ }^{1 *}$ and Mi-Ock Lee ${ }^{1 *}$ (D)
}

\begin{abstract}
Background: Nuclear receptor subfamily 1, group D, member 1 (NR1D1) is a ligand-regulated nuclear receptor and transcriptional factor. Although recent studies have implicated NR1D1 as a regulator of DNA repair and proliferation in breast cancers, its potential as a therapeutic target for breast cancer has not been assessed in terms of clinical outcomes. Thus, this study aims to analyze NR1D1 expression in breast cancer patients and to evaluate its potential prognostic value.
\end{abstract}

Methods: NR1D1 expression was analyzed by immunohistochemistry using an anti-NR1D1 antibody in 694 breast cancer samples. Survival analyses were performed using the Kaplan-Meier method with the log-rank test to investigate the association of NR1D1 expression with clinical outcome.

Results: One hundred thirty-nine of these samples exhibited high NR1D1 expression, mostly in the nucleus of breast cancer cells. NR1D1 expression correlated significantly with histological grade and estrogen receptor status. Overall survival (OS) and disease-free survival (DFS) did not correlate significantly with NR1D1 expression in breast cancer patients regardless of whether they had received chemotherapy. Subgroup analysis performed according to molecular subtype of breast cancer showed a significant influence of high NR1D1 expression on OS $(P=0.002)$ and DFS $(P=0.007)$ in patients with triple-negative breast cancer (TNBC) treated with chemotherapy.

Conclusions: High NR1D1 expression level had a favorable impact on OS and DFS in patients with TNBC treated with chemotherapy. NR1D1 should be investigated further as a possible prognostic marker in TNBC patients receiving chemotherapeutic treatment and as a target in the development of chemotherapeutic approaches to treating TNBC.

Keywords: NR1D1, TNBC, Chemotherapy, OS, DFS

\section{Background}

Breast cancer is the most common cancer and the main cause of cancer death in women worldwide [1]. It is a diverse and complex disease in terms of its histology and clinical outcomes. In recent decades, significant advances have been made in the molecular classification of breast cancer and in treatment strategies including prognostic prediction. The estrogen receptor (ER), progesterone receptor (PR),

\footnotetext{
*Correspondence: ykeeshin@snu.ac.kr; molee@snu.ac.kr

${ }^{1}$ College of Pharmacy, Bio-MAX, and Research Institute of Pharmaceutical

Sciences, Seoul National University, Seoul 08826, Republic of Korea

Full list of author information is available at the end of the article
}

and erb-b2 receptor tyrosine kinase 2 (ERBB2, also known as human epidermal growth factor receptor 2 (HER2)), are representative molecular biomarkers that distinguish breast cancer subtypes, i.e., $\mathrm{ER}^{+} / \mathrm{HER}^{-}, \mathrm{ER}^{+} / \mathrm{HER}^{+}, \mathrm{ER}^{-} / \mathrm{HER}^{+}$, and $\mathrm{ER}^{-} / \mathrm{HER} 2^{-}$[2]. Among these types of breast cancer, $\mathrm{ER}^{-} / \mathrm{HER} 2^{-}$breast cancer, also known as triple-negative breast cancer (TNBC), because of the lack of ER $\alpha, P R$, and ERBB2 expression, is the most aggressive subtype with advanced histological grade and poor clinical outcome despite appropriate treatment [3]. Because of the lack of appropriate targets, there is no specific systemic treatment such as endocrine therapy or HER2-targeted therapy for TNBC. At

(C) The Author(s). 2019 Open Access This article is distributed under the terms of the Creative Commons Attribution 4.0 International License (http://creativecommons.org/licenses/by/4.0/), which permits unrestricted use, distribution, and 
present, the basis of TNBC treatment is chemotherapy and radiotherapy, which are associated with serious side effects. Thus, the identification of new targets may provide benefits in the treatment of women with TNBC by minimizing the side effects.

One of the characteristics that make TNBC a more aggressive and malignant subtype is a defective DNA damage response system. For example, the incidence of the germline breast cancer 1 (BRCA1) mutations is relatively high in TNBC, and most BRCA1 mutation-associated breast cancers are TNBC [3]. Similarly, defects in genes related to DNA damage repair and genome maintenance, such as the Fanconi Anemia Complementation (FANC) group genes and 8-oxoguanine glycosylase 1, have been reported in TNBCs $[4,5]$. Given this strong association between TNBC and the defects in genes involved in DNA damage repair, understanding the DNA damage response system may provide important prognostic clues about TNBC.

Nuclear receptor subfamily 1 , group $\mathrm{D}$, member 1 (NR1D1), also known as REV-ERB $\alpha$, is a ligandregulated nuclear receptor and transcriptional factor that binds directly to specific DNA response elements and represses target gene transcription [6]. NR1D1 regulates diverse biological processes such as the circadian clocks, cellular differentiation, metabolism, immune responses, and behavior [7]. Several studies have reported that NR1D1 is closely associated with the pathophysiology of breast cancer. NR1D1 is located in the ERBB2 amplicon region of chromosome 17q12-21 and is thought to be part of the ERBB2 signature, which is associated with poor clinical outcome in breast cancer [8,9]. A synthetic NR1D1 agonist, SR9011, suppresses the proliferation of breast cancer cells regardless of the molecular subtype of breast cancer [10].

We recently reported a newly identified function of NR1D1, namely impairment of proper DNA repair. In breast cancer cells, NR1D1 is recruited to DNA damage sites and therein interacts with poly (ADP-ribose) polymerase 1 (PARP1) and subsequently inhibits the recruitment of the DNA damage response complex including SIRT6, pNBS1, and BRCA1 [11, 12]. Although NR1D1 may provide therapeutic options for improving the outcome of chemotherapy in breast cancer patients, its potential as a therapeutic target for breast cancer has not been clearly assessed in clinical outcomes. Therefore, in the present investigation, we performed a retrospective study to investigate NR1D1 expression in breast cancer patients and to evaluate its potential prognostic value.

\section{Methods}

Breast cancer tissue samples and patient information Primary breast carcinoma samples were obtained from Samsung Medical Center in Seoul, Korea, between 1995 and 2002. A total of 694 breast cancer patients were retrospectively investigated. This breast cancer cohort was from the Samsung Medical Center Breast Cancer Biomarker Study (SMC-BCBS) [13]. The clinicopathological data included age, tumor characteristics such as tumor size, lymph node (LN) involvement, LN metastasis, American Joint Committee on Cancer (AJCC) stage, and pathological stage. Adjuvant chemotherapy treatment and survival data were obtained from medical records (Table 1). Cases were classified into breast cancer subtypes, $\mathrm{ER}^{+} / \mathrm{HER}^{-}, \mathrm{ER}^{+} / \mathrm{HER}^{+}, \mathrm{ER}^{-} / \mathrm{HER}^{+}$, and TNBC. The protocol was approved by the ethical committees of the institutional review board (IRB) of the Samsung Medical Center (IRB File No. 2017-11-078).

\section{Immunohistochemical analysis}

The immunohistochemical analysis was performed as described previously [13]. Cores from breast cancer tissues were obtained, and tissue microarray paraffin blocks were generated. According to a routine protocol, the sections were deparaffinized with xylene, hydrated in serial dilutions of alcohol, and then were incubated in a $0.3 \%$ hydrogen peroxide solution for $15 \mathrm{~min}$ to neutralize endogenous peroxidase activity. Next, the sections were microwaved in citrate buffer for antigen retrieval. The tissue sections were then incubated for $1 \mathrm{~h}$ at room temperature with a primary antibody against NR1D1 (H00009572-M02, Novus Biologicals LCC, Littleton, CO, USA) diluted to a final concentration of 1:1000. Subsequently, the tissue sections were washed and reacted with an anti-mouse secondary antibody conjugated with a horseradish peroxidase-labeled polymer (K4001, Dako, Glostrup, Denmark) according to the manufacturers' instructions. The tissue sections were rinsed, and stained with liquid diaminobenzidine tetrahydrochloride, a highsensitivity substrate-chromogen system (K3468, DAKO, Glostrup, Denmark) for 5 min. Counterstaining was performed with Meyer's hematoxylin. The immunohistochemical staining was scored by pathologists based on the intensity of staining and percentage of stained tumor cells. The intensity of staining was scored as 0 , negative; 1 , weak; 2 , moderate; and 3 , strong. The percentage of stained tumor cells was quantified and scored from 0 to 4: 0 , negative or few; $1,<25 \% ; 2,25-50 \% ; 3,50-75 \%$; and $4,>75 \%$. The percentage and the staining intensity were then multiplied in order to generate the immunoreactive score for each of tumor specimens. Immunoreactive scores $0,1,2,3,4,6,8$, and 9 were classified as low NR1D1 expression, and score 12 was classified as high NR1D1 expression. The numbers of specimens in each immunohistochemical staining score were as follows: $0, n=3$ (0.4\%); $1, n=23$ (3.3\%); $2, n=69$ (9.9\%); $3, n=62$ (8.9\%); 4, $n=86$ (12.4\%); 6, $n=129$ (18.6\%); 8, $n=115$ (16.6\%); $9, n=68$ (9.8\%); and $12, n=139$ (20.0\%). 
Table 1 Characteristics of breast cancer patients and their NR1D1 expression level

\begin{tabular}{|c|c|c|c|c|c|c|}
\hline \multirow[t]{3}{*}{ Characteristics } & \multirow{2}{*}{\multicolumn{2}{|c|}{$\begin{array}{l}\text { All patients } \\
n=694\end{array}$}} & \multirow{2}{*}{\multicolumn{2}{|c|}{$\frac{\text { Low NR1D1 }}{n=555}$}} & \multirow{2}{*}{\multicolumn{2}{|c|}{$\frac{\text { High NR1D }}{n=139}$}} \\
\hline & & & & & & \\
\hline & No. & (\%) & No. & $(\%)$ & No. & $(\%)$ \\
\hline \multicolumn{7}{|c|}{ Age at diagnosis (years) } \\
\hline$\leq 50$ & 420 & 60.5 & 343 & 61.8 & 77 & 55.4 \\
\hline$>50$ & 274 & 39.5 & 212 & 38.2 & 62 & 44.6 \\
\hline \multicolumn{7}{|l|}{ Tumor size } \\
\hline $\mathrm{T} 1$ & 269 & 38.8 & 221 & 39.8 & 48 & 34.5 \\
\hline $\mathrm{T} 2$ & 378 & 54.5 & 292 & 56.2 & 86 & 61.9 \\
\hline T3 or T4 & 47 & 6.8 & 42 & 7.6 & 5 & 3.6 \\
\hline \multicolumn{7}{|l|}{ LN involvement } \\
\hline NO & 354 & 51.0 & 288 & 51.9 & 66 & 47.5 \\
\hline N1 & 180 & 25.9 & 142 & 25.6 & 38 & 27.3 \\
\hline N2 & 85 & 12.2 & 67 & 12.1 & 18 & 12.9 \\
\hline N3 & 75 & 10.8 & 58 & 10.5 & 17 & 12.2 \\
\hline
\end{tabular}

LN metastasis

$\begin{array}{lllllll}\text { Negative } & 354 & 51.0 & 288 & 51.9 & 66 & 47.5 \\ \text { Positive } & 340 & 49.0 & 267 & 48.1 & 73 & 52.5\end{array}$

AJCC stage

$\begin{array}{lllllll}\text { | } & 168 & 24.2 & 142 & 25.6 & 26 & 18.7 \\ \| & 353 & 50.9 & 275 & 49.5 & 78 & 56.1 \\ \text { III } & 173 & 24.9 & 138 & 24.9 & 35 & 25.2\end{array}$

Histologic grade

$\begin{array}{lllllll}1 & 76 & 11.0 & 69 & 12.4 & 7 & 5.0 \\ 2 & 246 & 35.4 & 201 & 36.2 & 45 & 32.4 \\ 3 & 323 & 46.5 & 246 & 44.3 & 77 & 55.4 \\ \text { Unknown } & 49 & 7.1 & 39 & 7.0 & 10 & 7.2\end{array}$

Estrogen receptor

$\begin{array}{lllllll}\text { Negative } & 282 & 40.6 & 213 & 38.4 & 69 & 49.6 \\ \text { Positive } & 411 & 59.2 & 341 & 61.4 & 70 & 50.4 \\ \text { Unknown } & 1 & 0.1 & 1 & 0.2 & 0 & 0.0\end{array}$

Progesterone receptor

$\begin{array}{llllllll}\text { Negative } & 379 & 54.6 & 298 & 53.7 & 81 & 58.3 & \\ \text { Positive } & 314 & 45.2 & 256 & 46.1 & 58 & 41.7 & \\ \text { Unknown } & 1 & 0.1 & 1 & 0.2 & 0 & 0.0 & \\ \text { HER2 amplification } & & & & & & & 0.113 \\ \text { Negative } & 504 & 72.6 & 411 & 74.1 & 93 & 66.9 & \\ \text { Positive } & 190 & 27.4 & 144 & 25.9 & 46 & 33.1 & \end{array}$

Breast cancer subtype

$\begin{array}{lllllll}\text { ER+/HER2- } & 334 & 48.1 & 281 & 50.6 & 53 & 38.1\end{array}$

$\begin{array}{lllllll}\text { ER+/HER2+ } & 97 & 14.0 & 74 & 13.3 & 23 & 16.5\end{array}$

$\begin{array}{lllllll}\text { ER-/HER2+ } & 92 & 13.3 & 69 & 12.4 & 23 & 16.5\end{array}$

$\begin{array}{lllllll}\text { TNBC (ER-/HER2-) } & 170 & 24.5 & 130 & 23.4 & 40 & 28.8\end{array}$

$\begin{array}{lllllll}\text { Undefined } & 1 & 0.1 & 1 & 0.2 & 0 & 0.0\end{array}$
Table 1 Characteristics of breast cancer patients and their NR1D1 expression level (Continued)

\begin{tabular}{|c|c|c|c|c|c|c|c|}
\hline \multirow[t]{3}{*}{ Characteristics } & \multirow{2}{*}{\multicolumn{2}{|c|}{$\begin{array}{l}\text { All patients } \\
n=694\end{array}$}} & \multirow{2}{*}{\multicolumn{2}{|c|}{$\begin{array}{l}\text { Low NR1D1 } \\
n=555\end{array}$}} & \multirow{2}{*}{\multicolumn{2}{|c|}{$\begin{array}{l}\text { High NR1D1 } \\
n=139\end{array}$}} & \multirow[b]{3}{*}{$P$ value } \\
\hline & & & & & & & \\
\hline & No. & $(\%)$ & No. & $(\%)$ & No. & (\%) & \\
\hline \multicolumn{3}{|c|}{ Adjuvant chemotherapy } & & & & & 0.649 \\
\hline No & 85 & 12.2 & 70 & 12.6 & 15 & 10.8 & \\
\hline Yes & 607 & 87.5 & 483 & 87.0 & 124 & 89.2 & \\
\hline Unknown & 2 & 0.3 & 2 & 0.4 & 0 & 0.0 & \\
\hline
\end{tabular}

${ }^{a}$ Chi-square test, $P$ values less than 0.05 are considered as significant changes and marked in italics

\section{Statistical analysis}

Correlations between NR1D1 expression and clinicopathological characteristics were analyzed using the chisquared test. Overall survival (OS) was defined as the time from the date of the primary surgery until the date of death or the last follow-up. Disease-free survival (DFS) was defined as the interval from the date of the primary surgery to the date of recurrence, which indicated locoregional recurrence, distant metastasis, or death from any cause. The Kaplan-Meier method was used for survival analysis, and the log-rank test was used to estimate the associations between variables and survival. A univariable logistic regression model was used to estimate the association of NR1D1 expression with clinicopathological factors. The multivariable Cox regression model was used to identify significant prognostic factors among the clinicopathological factors and NR1D1 expression. $P$ values $<0.05$ were considered as significant. The statistical analyses were performed using $\mathrm{R}$ software for statistical computing and graphics (http:// r-project.org).

\section{Results}

\section{Characteristics of breast cancer patients according to} NR1D1 expression

0.393 We used immunohistochemistry to analyze NR1D1 expression in primary invasive breast cancer specimens. A total of 694 patients who had informative immunohistochemical results were included in this study. A representative tissue microarray stained for NR1D1 is shown in Fig. 1. NR1D1 signals were found predominantly in the nuclei of tumor cells in almost all samples. Immunohistochemical staining scores were evaluated and classified into low- and high-NR1D1 expression groups. In these patients, the high-NR1D1 expression group score was 12 $(n=139)$ and the low-NR1D1 expression group score was $<12(n=555)$. The clinicopathological characteristics of the patients in the study cohort are summarized in Table 1. Most of the patients $(87.5 \%)$ were treated with adjuvant chemotherapy. We estimated the correlations of NR1D1 expression with clinicopathological 


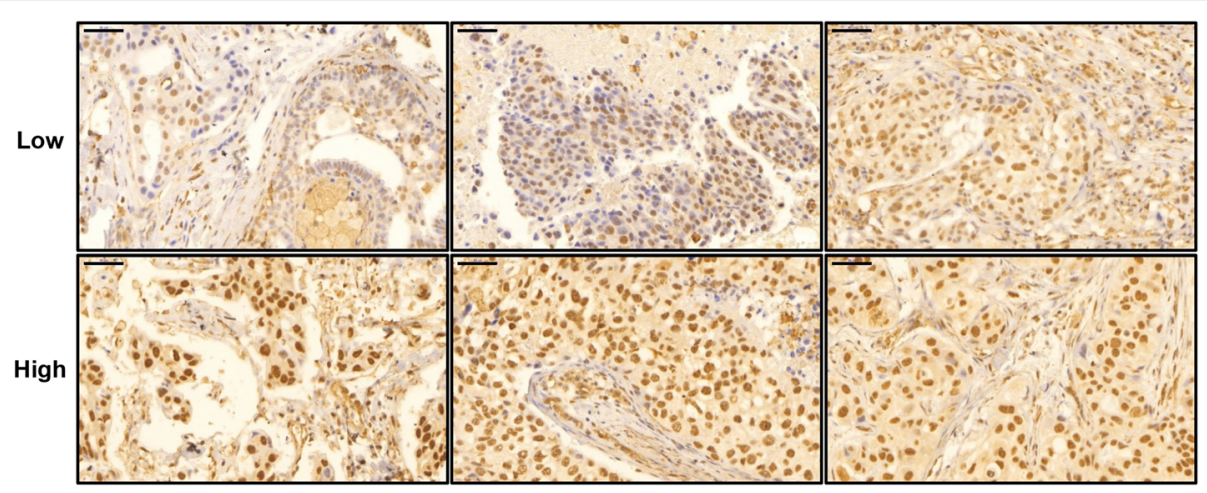

Fig. 1 Representative tissue microarray specimens stained for NR1D1. Immunoreactivity of representative tumor specimens is shown. Low and high NR1D1 expression groups are defined in methods. The low NR1D1 expression ranges from immunoreactive scores 2 to 6 (left (P2xl1), middle (P3X|1), and right (P3x|2)), and the high NR1D1 expression shows immunoreactive score 12 (all, P4X|3). P, percentage of stained tumor cells; I, intensity of staining. Scale bar, $50 \mu \mathrm{m}$

factors. NR1D1 expression correlated significantly with the clinicopathological feature histological grade $(P=0.011)$ and ER $\alpha$ status $(P=0.021)$. However, the correlations with other parameters including adjuvant chemotherapy were not significant (Table 1).

\section{Survival analysis}

The median follow-up times for OS and DFS were 10.3 years (range, 0.1-19.5 years) and 9.4 years (range, 0.1-19.5 years), respectively. During the follow-up, 28.6\% (198 of 692) of the patients had recurrence and/or metastasis, and $23.9 \%$ (165 of 691) of the patients died. To investigate the association of NR1D1 expression with clinical outcome, survival analyses were performed using the Kaplan-Meier method with the log-rank test. NR1D1 expression did not correlate significantly with OS $(P=0.266)$ or DFS $(P=0.387)$ in the breast cancer patients when all the samples were included in the analysis. In breast cancer patients who received chemotherapy, the OS $(P=0.254)$ and DFS $(P=0.243)$ did not differ significantly between groups with low or high NR1D1 expression (Fig. 2). Subgroup analyses according to molecular subtype of breast cancer in patients treated with chemotherapy showed significant influences of high NR1D1 expression on OS $(P=0.002)$ and DFS $(P=0.007)$ in TNBC patients who received chemotherapy (Fig. 3). These results suggest that high NR1D1 expression had a favorable effect on OS and DFS in TNBC patients treated with chemotherapy.

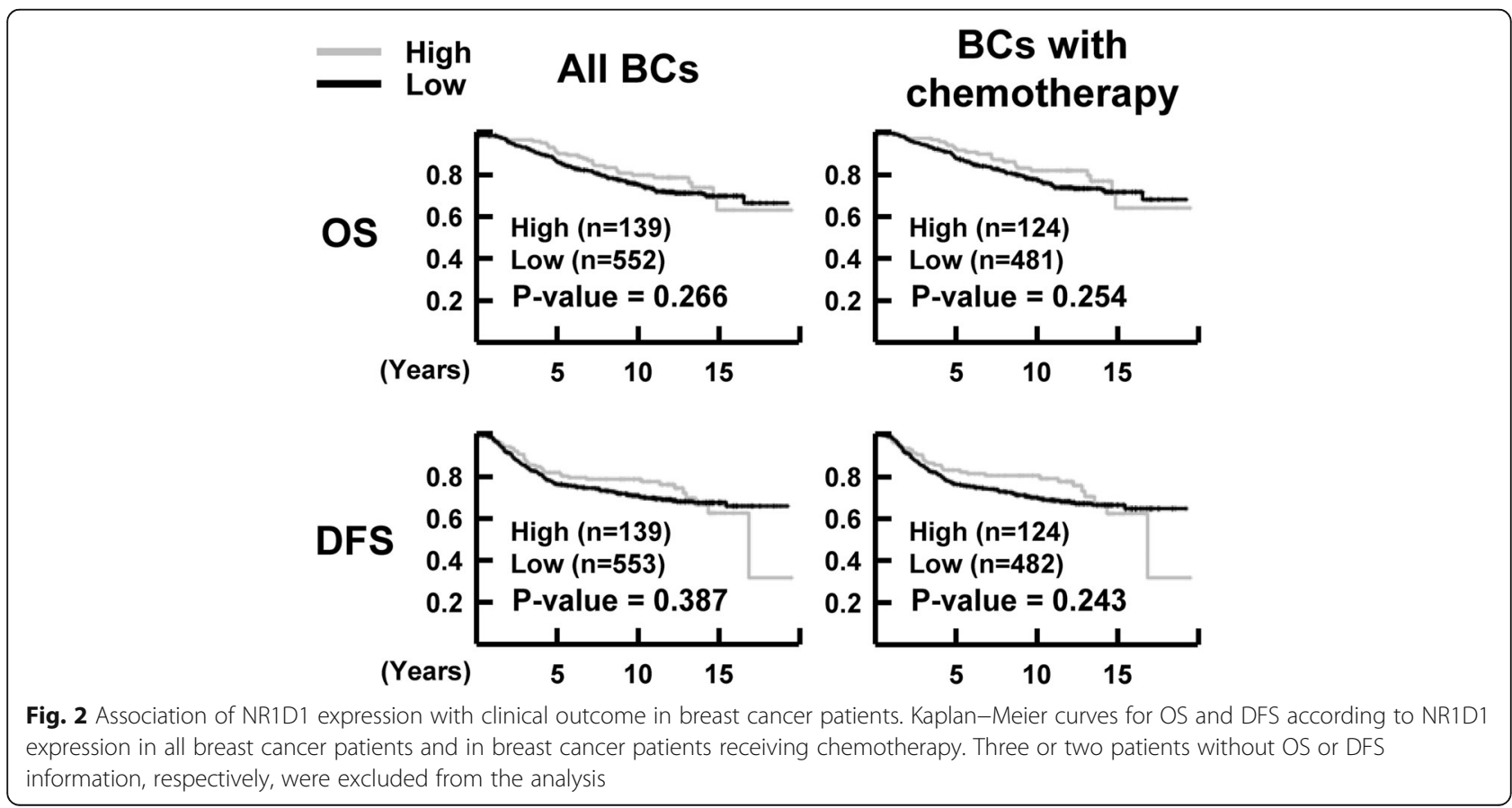




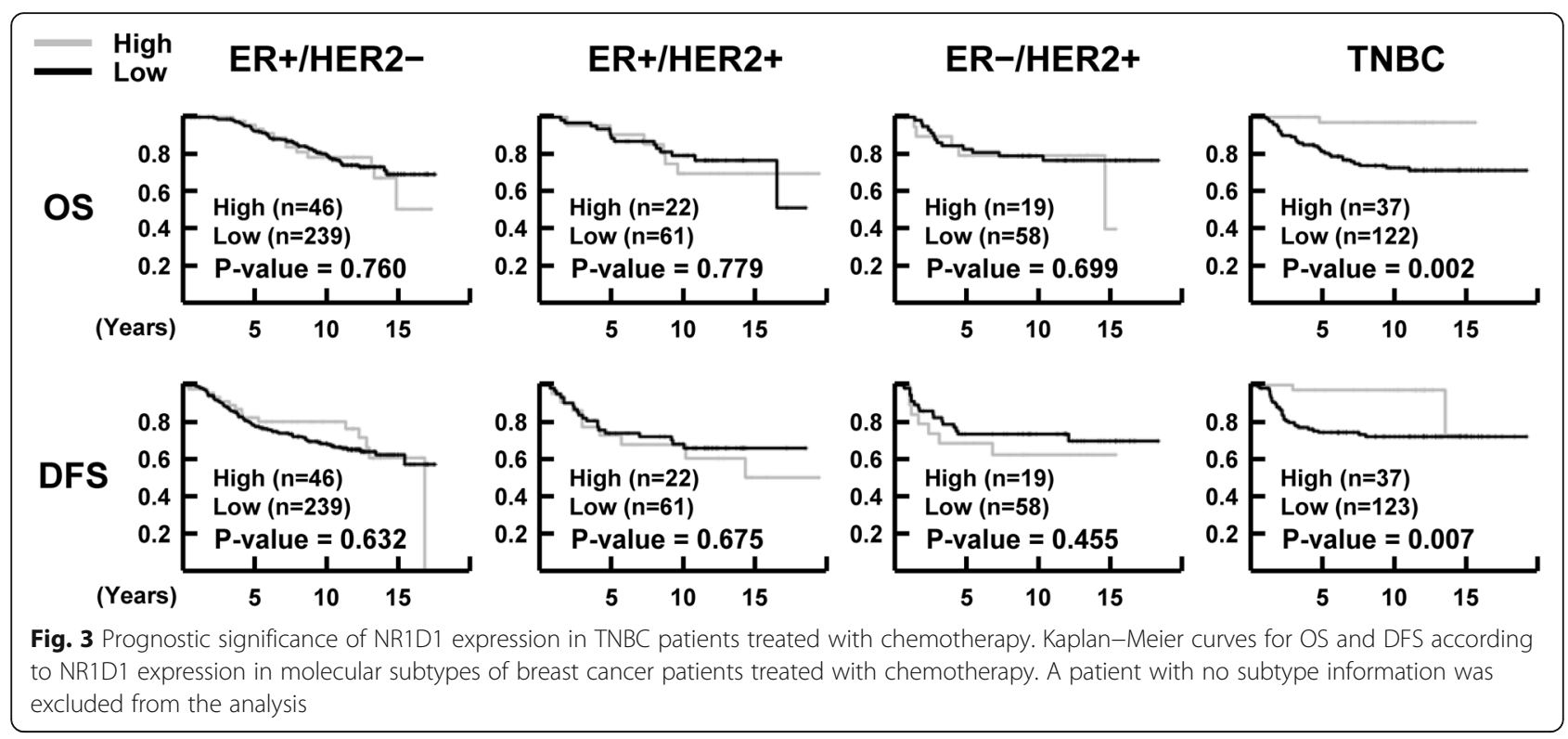

\section{Prognostic analysis}

Finally, we evaluated the association of NR1D1 expression with survival of TNBC patients who received chemotherapy. In the univariate analysis, after chemotherapy, TNBC patients with high NR1D1 expression had a greater probability of an improved OS and DFS than did those with low NR1D1 expression. The factors that predicted poor OS and DFS based on the univariate analysis were larger tumor size, presence of LN involvement, presence of LN metastasis, and advanced AJCC stage in TNBC patients who received chemotherapy (Table 2). To investigate this in depth, multivariate analysis was performed using Cox proportional hazard models that included the factors that were significant or marginal significant in the univariate analysis. The LN involvement was excluded because of the redundancy to LN metastasis and the small size of each subgroup. Importantly, NR1D1 expression in TNBC patients who received chemotherapy was significantly related to improvements in OS and DFS in the multivariate analysis. Our results suggest that high NR1D1 expression is associated with chemotherapeutic benefits and may be an independent prognostic factor in patients with TNBC (Table 3).

\section{Discussion}

Because of the lack of effective therapeutic targets, there is no specific systemic treatment for TNBC. Currently, TNBC treatment is typically based on chemotherapy and radiotherapy. Despite the standard chemotherapy regimens, TNBC patients respond differently to chemotherapy, ranging from early remission to worse OS $[14,15]$. Thus, identification of new biomarkers that can be used to predict the response to conventional TNBC therapy may be beneficial in the treatment of TNBC. In this study, we found that high NR1D1 expression had a favorable impact on OS and DFS in patients with TNBC treated with chemotherapy.

The DNA damage repair system is often defective in TNBC patients, and monitoring of the DNA damage response is an important prognostic clue. In TNBC patients, the expression of DNA damage repair genes, such as xeroderma pigmentosum complementation group $\mathrm{F}, F A N C$ group genes, PARP1, and RAD51, is associated with sensitivity to chemotherapy $[16,17]$. We recently reported that NR1D1 is a crucial component of the DNA damage response, which may suggest that a high expression level of NR1D1 increases the susceptibility of TNBC to DNA damage induced by chemotherapeutic agents and ultimately leading to a better OS in TNBC patients [11]. Although our previous study showed the inhibitory function of NR1D1 in DNA repair in MCF7 cells $\left(\mathrm{ER}^{+} / \mathrm{HER} 2^{-}\right)$, this function was also demonstrated in other molecular subtypes including BT474 $\left(\mathrm{ER}^{+} / \mathrm{HER}^{+}\right)$and MDA-MB-231 (TNBC) cells (data not shown). Interestingly, however, the prognostic effect of NR1D1 was exclusively found in TNBC and not in other subtypes. One possible explanation could be that gene variables that confer susceptibility to chemotherapy may vary according to molecular subtypes. For example, we showed previously that relative expression of proliferation-related and immune response-related genes, i.e., UBE2C, TOP2A, RRM2, FOXM1, MK167, and BTN3A2, provided a prediction value of adjuvant chemotherapy benefit for patients with $\mathrm{ER}^{+} / \mathrm{HER} 2^{-}$early breast cancer [18]. In $\mathrm{ER}^{-} / \mathrm{HER}^{+}$subtype, immune-related genes, i.e., BTN3A2, CD2, and TRBC1, and invasiveness-related MMP11 were significantly associated with a prognosis of this disease [19]. Thus, TNBCs could be the most susceptible subtype that are being benefited from 
Table 2 Univariate analysis of OS and DFS in the TNBC patients treated with chemotherapy

\begin{tabular}{|c|c|c|c|c|c|c|c|c|}
\hline \multirow[t]{2}{*}{ Variables } & \multicolumn{4}{|c|}{ OS } & \multicolumn{4}{|c|}{ DFS } \\
\hline & No. & $\mathrm{HR}$ & $95 \% \mathrm{Cl}$ & $P$ value & No. & $\mathrm{HR}$ & $95 \% \mathrm{Cl}$ & $P$ value \\
\hline \multicolumn{9}{|c|}{ NR1D1 expression } \\
\hline Low & 122 & 1.00 & & & 123 & 1.00 & & \\
\hline High & 37 & 0.09 & $0.01-0.63$ & 0.016 & 37 & 0.17 & $0.04-0.73$ & 0.017 \\
\hline \multicolumn{9}{|c|}{ Age at diagnosis } \\
\hline$\leq 50$ & 109 & 1.00 & & & 110 & 1.00 & & \\
\hline$>50$ & 50 & 1.25 & $0.62-2.55$ & 0.535 & 50 & 0.80 & $0.37-1.71$ & 0.564 \\
\hline \multicolumn{9}{|l|}{ Tumor size } \\
\hline $\mathrm{T} 1$ & 55 & 1.00 & & & 56 & 1.00 & & \\
\hline $\mathrm{T} 2$ & 93 & 2.16 & $0.87-5.36$ & 0.096 & 93 & 2.09 & $0.89-4.86$ & 0.089 \\
\hline $\mathrm{T} 3$ or $\mathrm{T} 4$ & 11 & 7.63 & $2.46-23.70$ & $<0.001$ & 11 & 4.58 & $1.34-15.68$ & 0.015 \\
\hline \multicolumn{9}{|c|}{ LN involvement } \\
\hline NO & 93 & 1.00 & & & 94 & 1.00 & & \\
\hline $\mathrm{N} 1$ & 36 & 1.03 & $0.36-2.94$ & 0.950 & 36 & 0.77 & $0.28-2.10$ & 0.607 \\
\hline N2 & 17 & 3.01 & $1.13-8.04$ & 0.028 & 17 & 2.18 & $0.85-5.57$ & 0.105 \\
\hline N3 & 13 & 15.26 & $6.46-36.05$ & $<0.001$ & 13 & 7.99 & $3.23-19.79$ & $<0.001$ \\
\hline \multicolumn{9}{|c|}{ LN Metastasis } \\
\hline No & 93 & 1.00 & & & 94 & 1.00 & & \\
\hline Yes & 66 & 2.79 & $1.37-5.66$ & 0.005 & 66 & 1.77 & $0.90-3.46$ & 0.099 \\
\hline \multicolumn{9}{|l|}{ AJCC stage } \\
\hline I & 42 & 1.00 & & & 43 & 1.00 & & \\
\hline$\|$ & 84 & 1.55 & $0.50-4.74$ & 0.446 & 84 & 1.64 & $0.60-4.48$ & 0.333 \\
\hline III & 33 & 6.65 & $2.22-19.93$ & $<0.001$ & 33 & 4.49 & $1.60-12.63$ & 0.004 \\
\hline \multicolumn{9}{|c|}{ Histologic grade } \\
\hline 1 & 3 & - & & & 3 & - & & \\
\hline 2 & 31 & 1.00 & & & 31 & 1.00 & & \\
\hline 3 & 99 & 1.86 & $0.64-5.39$ & 0.251 & 100 & 1.57 & $0.60-4.14$ & 0.358 \\
\hline Unknown & 26 & - & - & - & 26 & - & - & - \\
\hline
\end{tabular}

$P$ values less than 0.05 are considered as significant changes and marked in italics $H R$ hazard ratio, $\mathrm{Cl}$ confidential interval

the high intratumoral expression of NR1D1 after treatment with DNA damaging chemotherapy.

Interestingly, several studies have reported that genetic polymorphism of NR1D1 is associated with human diseases such as bipolar disorder and obesity [20-23]. The variations were located mainly in the first intron and in the 5' untranslated region of NR1D1, which may cause differential expression of the gene, as shown in breast cancer patients. Thus, the role of genetic variations in NR1D1 in the pathogenesis and progression of breast cancer as well as the chemotherapeutic responses may be an important issue. More detailed analyses of the polymorphisms and expression level of NR1D1 together with genomic analysis for defects in DNA damage repair genes may provide prediction value for clinical outcomes of adjuvant chemotherapy in TNBC patients.
Because $10-20 \%$ of breast cancers are TNBC, identification of new targets that could maximize the efficacy but minimize the side effects of chemotherapy is an unmet need [24]. Recently, small molecules that can modulate the activity of NR1D1 and their potential as anticancer therapeutics were demonstrated [25]. SR9011, a synthetic ligand of NR1D1, has been reported to inhibit the proliferation of various breast cancer cell lines and to induce cell cycle arrest by suppressing cyclin A [10]. Because NR1D1 increases DNA damage induced by chemotherapeutic agents, the potential of combining chemotherapy with ligands of NR1D1 may be a therapeutic option for a more effective approach. GSK4112, a synthetic ligand of NR1D1, increased the chemosensitivity of breast cancer cells to doxorubicin [11]. In conclusion, our study suggests that the expression level of NR1D1 is both a prognostic marker for patients under 
Table 3 Multivariate analysis of OS and DFS in the TNBC patients treated with chemotherapy

\begin{tabular}{|c|c|c|c|c|c|c|c|c|}
\hline \multirow[t]{2}{*}{ Variables } & \multicolumn{4}{|c|}{ OS } & \multicolumn{4}{|c|}{ DFS } \\
\hline & No. & $\mathrm{HR}$ & $95 \% \mathrm{Cl}$ & $P$ value & No. & $\mathrm{HR}$ & $95 \% \mathrm{Cl}$ & $P$ value \\
\hline \multicolumn{9}{|c|}{ NR1D1 expression } \\
\hline Low & 122 & 1.00 & & & 123 & 1.00 & & \\
\hline High & 37 & 0.09 & $0.01-0.65$ & 0.017 & 37 & 0.16 & $0.04-0.68$ & 0.013 \\
\hline \multicolumn{9}{|l|}{ Tumor size } \\
\hline $\mathrm{T} 1$ & 55 & 1.00 & & & 56 & 1.00 & & \\
\hline $\mathrm{T} 2$ & 93 & 0.76 & $0.14-4.13$ & 0.753 & 93 & 0.73 & $0.14-3.79$ & 0.705 \\
\hline $\mathrm{T} 3$ or T4 & 11 & 1.05 & $0.15-7.37$ & 0.963 & 11 & 0.76 & $0.10-5.65$ & 0.793 \\
\hline \multicolumn{9}{|c|}{ LN metastasis } \\
\hline No & 93 & 1.00 & & & 94 & 1.00 & & \\
\hline Yes & 66 & 0.97 & $0.27-3.57$ & 0.967 & 66 & 0.64 & $0.19-2.19$ & 0.474 \\
\hline \multicolumn{9}{|l|}{ AJCC stage } \\
\hline 1 & 42 & 1.00 & & & 43 & 1.00 & & \\
\hline$\|$ & 84 & 2.36 & $0.30-18.35$ & 0.413 & 84 & 3.02 & $0.43-21.03$ & 0.265 \\
\hline III & 33 & 8.61 & $0.52-144.06$ & 0.134 & 33 & 10.53 & $0.71-157.21$ & 0.088 \\
\hline
\end{tabular}

$P$ values less than 0.05 are considered as significant changes and marked in italics $H R$ hazard ratio, $\mathrm{Cl}$ confidential interval

chemotherapeutic treatment and a target for the development of chemotherapeutic approaches for the treatment of TNBC.

\section{Conclusions}

Although NR1D1 implicates as a regulator of DNA repair and proliferation in breast cancers, its potential as a therapeutic target for breast cancer has not been assessed in clinical outcomes. Our data showed that high NR1D1 expression had a favorable impact on OS and DFS in patients with TNBC treated with chemotherapy. NR1D1 should be investigated further as a possible prognostic marker in TNBC patients receiving chemotherapeutic treatment and as a target in the development of chemotherapeutic approaches to treating TNBC.

\section{Abbreviations}

AJCC: American Joint Committee on Cancer; BRCA1: Breast cancer 1; DFS: Disease-free survival; ER: Estrogen receptor; ERBB2: erb-b2 receptor tyrosine kinase 2; FANC: Fanconi Anemia Complementation; HER2: Human epidermal growth factor receptor 2; LN: Lymph node; NR1D1: Nuclear receptor subfamily 1 , group $D$, member 1 ; OS: Overall survival; PARP1: Poly(ADP-ribose) polymerase 1; PR: Progesterone receptor; TNBC: Triple-negative breast cancer

\section{Acknowledgements}

Not applicable.

\section{Authors' contributions}

MOL and YKS conceived and designed this study. HN, NLK, MHL, and YLC were involved in data acquisition. JH performed the statistical analyses. HN, $J \mathrm{H}, \mathrm{YKS}$, and MOL analyzed and interpreted the data. HN, YKS, and MOL drafted the manuscript. MOL and YKS supervised the overall study. All authors reviewed and approved the final version of the manuscript.

\section{Funding}

This work was supported by grants from the National Research Foundation of Korea (2014M3A9D5A01073556, 2017R1A2B3011870, 2018R1A5A2024425, and BK21 Plus program)

\section{Availability of data and materials}

The datasets used and/or analyzed during the current study are available from the corresponding author on reasonable request.

\section{Ethics approval and consent to participate}

This study was approved by the ethical committees of the IRB of the Samsung Medical Center. The study was retrospective, and consent to participate was not required, as per the guidelines of the IRB.

\section{Consent for publication}

Not applicable.

\section{Competing interests}

$\mathrm{JH}$ is a salaried employee of Gencurix, Inc. HN, NLK, YKS, and MOL hold a patent application related to the content of this article. The other authors declare that they have no competing interests.

\section{Author details}

${ }^{1}$ College of Pharmacy, Bio-MAX, and Research Institute of Pharmaceutical Sciences, Seoul National University, Seoul 08826, Republic of Korea. ${ }^{2}$ Gencurix, Inc, Seoul 08394, Republic of Korea. ${ }^{3}$ Department of Pathology, Samsung Medical Center, Sungkyunkwan University School of Medicine, Seoul, Republic of Korea.

Received: 6 April 2018 Accepted: 4 September 2019

Published online: 28 November 2019

References

1. Torre LA, Bray F, Siegel RL, Ferlay J, Lortet-Tieulent J, et al. Global cancer statistics, 2012. CA Cancer J Clin. 2015;65:87-108.

2. Schnitt SJ. Classification and prognosis of invasive breast cancer: from morphology to molecular taxonomy. Modern Phathol. 2010;23:560-4.

3. Reis-Filho JS, Tutt AN. Triple negative tumours: a critical review. Histopathology. 2008:52:108-18.

4. Karihtala P, Kauppila S, Puistola U, Jukkola-Vuorinen A. Absence of the DNA repair enzyme human 8-oxoguanine glycosylase is associated with an aggressive breast cancer phenotype. Br J Cancer. 2012;106:344-7. 
5. Ribeiro E, Ganzinelli M, Andreis D, Bertoni R, Giardini R, et al. Triple negative breast cancers have a reduced expression of DNA repair genes. PLoS One. 2013;8:e66243

6. Everett LJ, Lazar MA. Nuclear receptor Rev-erba: up, down, and all around. Trends Endocrinol Metab. 2014;25:586-92.

7. Kojetin DJ, Burris TP. REV-ERB and ROR nuclear receptors as drug targets. Nat Rev Drug Discov. 2014;13:197-216.

8. Chin K, DeVries S, Fridlyand J, Spellman PT, Roydasgupta R, et al. Genomic and transcriptional aberrations linked to breast cancer pathophysiologies. Cancer Cell. 2006;10:529-41.

9. Davis LM, Harris C, Tang L, Doherty P, Hraber P, et al. Amplification patterns of three genomic regions predict distant recurrence in breast carcinoma. J Mol Diagn. 2007:9:327-36.

10. Wang Y, Kojetin D, Burris TP. Anti-proliferative actions of a synthetic REVERBa/ $\beta$ agonist in breast cancer cells. Biochem Pharmacol. 2015:96:315-22.

11. Ka NL, Na TY, Na H, Lee MH, Park HS, et al. NR1D1 recruitment to sites DNA damage inhibits repair and is associated with chemosensitivity of breast cancer. Cancer Res. 2017;77:2453-63.

12. Ka NL, Na TY, Lee MO. NR1D1 enhances oxidative DNA damage by inhibiting PARP1 activity. Mol Cell Endocrinol. 2017;454:87-92.

13. Choi YL, Oh E, Park S, Kim Y, Park YH, et al. Triple-negative, basal-like, and quintuple-negative breast cancers: better prediction model for survival. BMC Cancer. 2010;10:507-21.

14. Lehmann BD, Bauer JA, Chen X, Sanders ME, Chakravarthy AB, et al. Identification of human triple-negative breast cancer subtypes and preclinical models for selection of targeted therapies. J Clin Invest. 2011;121: 2750-67.

15. Masuda H, Baggerly KA, Wang Y, Zhang Y, Gonzalez-Angulo AM, et al. Differential response to neoadjuvant chemotherapy among 7 triplenegative breast cancer molecular subtypes. Clin Cancer Res. 2013;19: 5533-340.

16. Alexander BM, Sprott K, Farrow DA, Wang X, D'Andrea AD, et al. DNA repair protein biomarkers associated with time to recurrence in triple-negative breast cancer. Clin Cancer Res. 2010;16:5796-804.

17. Rodriguez AA, Makris A, Wu MF, Rimawi M, Froehlich A, et al. DNA repair signature is associated with anthracycline response in triple negative breast cancer patients. Breast Cancer Res Treat. 2010;123:189-96.

18. Kwon MJ, Lee SB, Han J, Lee JE, Lee JW, et al. BCT score predicts chemotherapy benefit in Asian patients with hormone receptor-positive, HER2-negative, lymph node-negative breast cancer. PLoS One. 2018;13: e0207155.

19. Han J, Kim H, Choi JY, Lee SK, Lee JE, et al. MMP11 and CD2 as novel prognostic factors in hormone receptor-negative, HER2-positive breast cancer. Breast Cancer Res Treat. 2017:164:41-56.

20. Severino G, Manchia M, Contu P, Squassina A, Lampus S, et al. Association study in a Sardinian sample between bipolar disorder and the nuclear receptor REV-ERBalpha gene, a critical component of the circadian clock system. Bipolar Disord. 2009;11:215-20.

21. McCarthy MJ, Nievergelt CM, Shekhtman T, Kripke DF, Welsh DK, et al. Functional genetic variation in the Rev-Erba pathway and lithium response in the treatment of bipolar disorder. Genes Brain Behav. 2011;10:852-61.

22. Goumidi L, Grechez A, Dumont J, Cottel D, Kafatos A, et al. Impact of REVERB alpha gene polymorphisms on obesity phenotypes in adult and adolescent samples. Int J Obes. 2013;37:666-72.

23. Ruano EG, Canivell S, Vieira E. REV-ERB ALPHA polymorphism is associated with obesity in the Spanish obese male population. PLoS One. 2014;9: e104065.

24. Bianchini G, Balko JM, Mayer IA, Sanders ME, Gianni L. Triple-negative breast cancer: challenges and opportunities of a heterogeneous disease. Nat Rev Clin Oncol. 2016;13:674-90.

25. Son GH, Chung S, Ramirez VD, Kim K. Pharmacological modulators of molecular clock and their therapeutic potentials in circadian rhythm-related diseases. Med Chem (Los Angeles). 2016;6:724-33.

\section{Publisher's Note}

Springer Nature remains neutral with regard to jurisdictional claims in published maps and institutional affiliations.

\section{Ready to submit your research? Choose BMC and benefit from:}

- fast, convenient online submission

- thorough peer review by experienced researchers in your field

- rapid publication on acceptance

- support for research data, including large and complex data types

- gold Open Access which fosters wider collaboration and increased citations

- maximum visibility for your research: over $100 \mathrm{M}$ website views per year

At BMC, research is always in progress.

Learn more biomedcentral.com/submissions 